quent rinsing and wiping. Practically the easiest way to bring a plate back to its original condition is to rub it with soapy water. But even this does not fully succeed with the test-tube, probably on account of the less effective rubbing and wiping near the closed end. But what exactly is involved in rubbing and wiping? I ventured to suggest before that possibly grease may penetrate the glass somewhat. From such a situation it might not easily be removed, or, on the other hand, introduced.

There is another form of experiment from which I had hoped to reap decisive results. The interior of a mass of glass cannot be supposed to be greasy, so that a surface freshly obtained by fracture should be clean, and give the dark deposit. One difficulty is that the character of the deposit on the irregular surface is not so easily judged. My first trial on a piece of plate glass $\frac{3}{8}$ in. thick, broken into two pieces with a hammer, gave anomalous results. On part of each new surface the breath was deposited in thin laminæ capable of showing colours, but on another part the water masses were decidedly smaller, and the deposit could scarcely be classified as black. The black and less black parts of the two surfaces were those which had been contiguous before fracture. That there should be a well-marked difference in this respect between parts both inside a rather small piece of glass is very surprising. I have not again met with this anomaly; but further trials on thick glass have revealed deposits which may be considered dark, though I was not always satisfied that they were so dark as those obtained on flat surfaces with the blow-pipe or hot sulphuric acid. Similar experiments with similar results may be made upon the edges of ordinary glass plates (such as are used in photography), cut with a diamond. The breath deposit is best held pretty close to a candle-flame, and is examined with a magnifier.

In conclusion, I may refer to two other related matters in which my experience differs from that of Mr. Aitken. He mentions that with an alcohol flame he "could only succeed in getting very slight indications of any action." I do not at all understand this, as I have nearly always used an alcohol flame (with a mouth blow-pipe) and got black deposits. Thinking that perhaps the alcohol which I generally use was contaminated, I replaced it by pure alcohol, but without any perceptible difference in the results.

Again, I had instanced the visibility of a gas flame through a dewed plate as proving that part of the surface was uncovered. I have improved the experiment by using a curved tube through which to blow upon a glass plate already in position between the flame and the eye. I have not been able to find that the flame becomes invisible (with a well-defined outline) at any stage of the deposition of dew. Mr. Aitken mentions results pointing in the opposite direction. Doubtless, the highly localised light of the flame is favourable.

NO. $225 \mathrm{I}$, VOL 90]

\section{PALAEOLITHIC MAN.}

THE fossil human skull and mandible to be described by Mr. Charles Dawson and Dr. Smith Woodward at the Geological Society as we go to press is the most important discovery of its kind hitherto made in England. The specimen was found in circumstances which seem to leave no doubt as to its geological age, and the characters it shows are themselves sufficient to denote its extreme antiquity. It was met with in a gravel which was deposited by the river Ouse near Piltdown Common, Fletching, Sussex, at a time when that river flowed at a level eighty feet above its present course.

Although the basin of the stream is now well within the Weald and far removed from the chalk, the gravel consists largely of iron-stained flints closely resembling those well known in gravel deposits on the downs, and among these there are many waterworn "eoliths" identical with those found on the chalk plateau near Ightham, Kent.

With the flints were discovered two fragments of the molar tooth of a Pliocene elephant, and a waterworn cusp of the molar of a Mastodon. The gravel is therefore partly made up of the remains of a Pliocene land-deposit. Teeth of hippopotamus, beaver, and horse, and part of the antler of a red deer were also found, with several unabraded typical early Palæolithic (Chellean) implements. The latter seem to determine the age of the gravel as Lower Pleistocene.

The human remains, which are in the same mineralised condition as the associated fragments of other mammals, comprise the greater part of the brain-case and one mandibular ramus which lacks the upper portion of the symphysis. The skilit measures $190 \mathrm{~mm}$. in length by $150 \mathrm{~mm}$. in width at its widest part, and the bones are of nearly twice the normal thickness. Its brain capacity is about io7o c.c. The forehead is much steeper than in the Neanderthal type, with only a feeble brow-ridge; and the back of the skull is remarkably low and broad, indicating an ape-shaped neck. The mandible, so far as preserved, is identical in form with that of a young chimpanzee, showing even the characteristically simian inwardly curved flange of bone at the lower border of the retreating symphysis. The two molars preserved are of the human pattern, but comparatively long and narrow.

At least one very low type of man with a high forehead was therefore in existence in western Europe long before the low-browed Neanderthal man became widely spread in this region. Dr. Smith Woodward accordingly inclines to the theory that the Neanderthal race was a degenerate offshoot of early man and probably became extinct, while surviving modern man may have arisen directly from the primitive source of which the Piltdown skull provides the first discovered evidence. 